\title{
Moral Rights Protection for the Visual Arts
}

By

Melissa Boyle, Debra O'Connor, and Stacy Nazzaro

August 2008

\section{COLLEGE OF THE HOLY CROSS, DEPARTMENT OF ECONOMICS \\ FACULTY RESEARCH SERIES, PAPER NO. 08-09*}

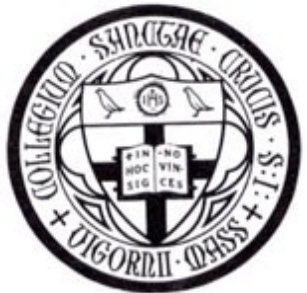

Department of Economics

College of the Holy Cross

Box 45A

Worcester, Massachusetts 01610

(508) 793-3362 (phone)

(508) 793-3708 (fax)

http://www.holycross.edu/departments/economics/website

*All papers in the Holy Cross Department of Economics Faculty Research Series should be considered works in progress. Comments and suggestions are welcome. 


\title{
Moral Rights Protection for the Visual Arts
}

\author{
Melissa Boyle ${ }^{\dagger}$ \\ By \\ Lake Forest College \\ Debra O'Connor ${ }^{\dagger \dagger}$
College of the Holy Cross \\ and \\ Stacy Nazzaro ${ }^{\dagger \dagger \dagger}$ \\ College of the Holy Cross
}

August 2007

\begin{abstract}
Beginning in 1979, certain states extended extra copyright protection, known as "moral rights" protection, to visual artists. Moral rights protection, which was incorporated into U.S. copyright law in 1990, ensures that works cannot be altered in a manner that would negatively impact the reputation of the artist. Using difference-in-differences regression strategies, we compare artists and non-artists in states with moral rights laws to those in states without these laws, before and after the laws are enacted. This enables us to test the impact of the laws on the behavior of artists, consumers, and policy makers. Our analysis reveals that artists' incomes fall by over $\$ 4,000$ per year as a result of moral rights legislation, but we find no impact of the laws on artists' choices of residence or on state-level public spending on the arts.
\end{abstract}

JEL Classification Codes: Z11

Keywords: copyright, moral rights, Visual Artists Rights Act of 1990 (VARA)

This research was supported by a grant to Holy Cross from the May and Stanley Smith Charitable Trust.

${ }^{\dagger}$ Melissa Boyle, Department of Economics, Box 191A College of the Holy Cross, Worcester, MA 01610, mboyle@holycross.edu, 508-793-2334 (phone), 508-793-3710 (fax)

${ }^{\dagger}$ Debra O'Connor, Department of Economics, Box 198A College of the Holy Cross, Worcester, MA 01610, doconnor@holycross.edu, 508-793-2689 (phone), 508-793-3710 (fax)

${ }^{\dagger \dagger}$ Stacy Nazzaro, Department of Economics, College of the Holy Cross, Worcester, MA 01610,smnazz10@holycross.edu 


\section{Introduction}

Beginning in 1979, California extended extra copyright protection, known as "moral rights" protection, to visual artists. Moral rights protection ensures that works of art cannot be altered in a manner that would negatively impact the reputation of the artist. Although several other states ${ }^{1}$ have enacted some form of moral rights legislation since 1979, the moral rights of artists were not recognized at the federal level in the United States prior to the enactment of the Visual Artists Rights Act of 1990 (VARA). After 1990, state laws were therefore preempted by VARA, except where state and federal law do not overlap (17 U.S.C. § 301 (f)).

VARA, which is part of U.S. copyright law, gives visual artists $^{2}$ the rights of attribution and integrity. The right of attribution gives the author of a work of visual art a right to claim ownership of that work and to prevent the use of his or her name as the author of any work he or she did not create (17 U.S.C. § 106A (1)). Therefore, the artist may prevent the use of his or her name as the creator of a work "in the event of distortion, mutilation, or other modification of the work which would be prejudicial to his or her honor or reputation” (17 U.S.C. $§ 106 A(2))$. The right of integrity allows an artist to prevent any intentional alterations to a work which would damage his or her reputation (17 U.S.C. § 106A (3)). Only the artist is given the right to enforce the rights of integrity

\footnotetext{
${ }^{1}$ New York, Massachusetts, Maine, Louisiana, New Jersey, Pennsylvania, New Mexico, Rhode Island, Connecticut, Nevada, South Dakota, Montana, and Utah.

${ }^{2}$ In particular, VARA applies to paintings, drawings, sculptures, prints, and still photographs produced for exhibition (single copies or signed and numbered limited editions of 200 or less) for works created after June 1, 1991 (17 U.S.C. § 101). There is a limitation for art work that is part of a building, and would likely to be mutilated or destroyed if later removed. VARA also does not cover the alteration, mutilation or destruction of a work that results from negligence, the passage of time, the nature of the materials used, or failed conservation efforts. Finally, VARA does not protect a "work-for-hire" which is defined by the Copyright Act as "a work prepared by an employee within the scope of his or her employment" (17 U.S.C. $\S 101)$.
} 
and attribution and only for his or her lifetime. ${ }^{3}$ When the work is of "recognized stature,” the right of integrity also includes the right to prevent any intentional or grossly negligent destruction of that work. ${ }^{4}$ A critical aspect of VARA is that moral rights can be waived, although not transferred, for a specific person for a specific use, so long as the artist consents in writing (17 U.S.C. § 106A (e)).

From a theoretical standpoint, the impact of moral rights legislation on social welfare is ambiguous. On the one hand, the laws provide buyers with the secure knowledge that their artistic investments will not be devalued through the alteration of other pieces created by the artist. By the same token, the laws potentially serve the general public by ensuring that important works of art remain intact and available for public consumption (Hansmann and Santilli 1997). This should also positively impact the utility of artists, both by potentially increasing income, and because of the non-pecuniary benefits associated with the protection of one's reputation. Thus, proponents of moral rights laws argue that they increase the incentive for artists to produce, leading to a greater stock of innovative art. On the other hand, some economists (e.g. Landes 2001, Landes and Levine 2006) have argued that moral rights legislation most likely does not enhance social welfare and may even lead to net welfare decreases. They point out that the costs of these laws may be higher than the benefits, particularly because the limitations imposed by the laws may deter buyers, and as a result many artists draw up legal contracts waiving their moral rights. The transaction costs associated with such waivers may lead to a loss in income and overall utility for artists.

\footnotetext{
${ }^{3}$ This is in contrast to the rest of U.S. copyright law, which extends protection for 70 years after the death of the artist. In addition, moral rights are retained by the artist even if the copyright has been transferred.

4 "Recognized stature" is not defined in the code, but is determined on a case- by-case basis (St. Louis Volunteer Lawyers and Accountants for the Arts 2005).
} 
With the exception of one study (Landes 2001), there has been little effort to empirically analyze the economic impact of moral rights protection. We therefore add to the existing literature by estimating the effect of state-level (i.e. pre-VARA) moral rights legislation on artists' incomes and locational decisions, using a difference-in-differences framework. We find that state moral rights legislation leads to a reduction in artists' incomes, but find no evidence that artists move as a result, implying that the nonmonetary benefits the laws provide may outweigh the financial losses to artists.

\section{Background and Previous Literature}

Although the Visual Artists Rights Act of 1990 has been in place for eighteen years, the United States was not the forerunner in the introduction of moral rights legislation. As early as the nineteenth century, French courts identified a series of rights for artists based on the legal concept of le droit moral. In France and other European countries, these moral rights were construed as inalienable natural rights of the creator. These moral rights laws consider art work as "literal extensions of the artist's soul or creative being; since the artist's personality is embodied in the products of his or her labor, to attack or misrepresent the work is, in effect, to attack or slander a person (hence the term moral rights).”(Failing 2002)

Since 1928, moral rights have been codified in the international copyright treaty known as the Berne Convention. Nations that are members of the Berne Convention are required to meet a minimum level of moral rights protection. Additional moral rights protection beyond the minimum level can vary from nation to nation. For example, France provides broad protection for the artist, while in the United Kingdom, artists rely 
more on contract law than copyright law for moral rights protection (U.S. Copyright Office 1996). Canada has had moral rights laws since 1924, and was the first common law country to enact specific moral rights legislation (Rushton 1998). The United States became a member of the Berne Convention in 1989 and slightly expanded that scope of protection of moral rights by enacting VARA in 1990 (Chang 2004). ${ }^{5}$

Several papers have discussed the economic implications of moral rights laws. Hansmann and Santilli (1997) contend that moral rights laws can have both pecuniary and non-pecuniary benefits to the artist, owners of the artist's work, and the public by controlling "reputational” externalities - i.e. the negative impact on the public and other owners that may result should one owner alter a work in a way that damages the reputation of the artist. They do point out however, that the destruction of one piece of an artist's work has an ambiguous effect on the prices for the remaining stock of the artist's product, since the decrease in supply of close substitutes may alternatively cause prices to rise. Rushton (1998) argues that a case can be made for restricting the alienability of moral rights, based on externalities potentially suffered by the public and other owners of an artist's work, should the actions of one owner injure the artist's reputation. In a later paper, he concludes that "restrictions on the waivability of moral rights [are] more about ensuring a fair process of contracting rather than inhibiting mutually beneficial transactions” (Rushton 2001, p. 256).

While the previous authors discuss some possible social welfare gains from moral rights legislation, Landes (2001) unequivocally rejects the argument that moral rights laws encourage artistic innovation, thus increasing the supply of high-quality art. He

\footnotetext{
${ }^{5}$ See Landes (2001) and Landes and Levine (2006) for a thorough discussion of the various court cases related to this legislation.
} 
suggests that these laws are likely inefficient and potentially harm the very parties they are intended to protect. Landes dismisses the reputational externalities argument, pointing out that no owner should have the incentive to alter a work in a way that would decrease its value. He additionally suggests that should such an alteration occur, the artist's reputation would not suffer as long as it is known that the artist himself is not responsible for the altered work. Landes indicates that prior to VARA, all artists had the ability to protect their integrity rights under contract law. The lack of evidence of such contracts implies that the costs of establishing such protection likely outweighed the benefits. In addition, Landes demonstrates that many artists who understand their ability to waive these rights under VARA, do so. This implies that the benefits of no protection (e.g. easier sale of the work) are higher than the costs of being covered under the law. Landes thus concludes that mandating the protection of integrity rights under VARA simply adds unnecessary transaction costs and is economically inefficient. Landes also argues that most attribution rights afforded by VARA were previously covered under tort law and unfair competition law, rendering that section of the law redundant.

In addition to thoroughly describing the law and economics of moral rights legislation, Landes presents an empirical analysis designed to test the various theoretical predictions described above. Utilizing state-level, cross-sectional data from 1990, that study estimates OLS regressions to measure the impact of moral rights protection on artists' earnings and locational decisions, and on state art agency appropriations. Results show no statistically significant effect of moral rights protection on any of these three outcomes, but various drawbacks to the estimation strategy open the door for further empirical study. Because Landes employs a state-level analysis in a one-year cross- 
section, regressions are run on a very small number of observations. In addition, these results are potentially biased by unobservable and possibly systematic differences between law and non-law states. For instance, states previously providing a more supportive environment to visual artists might attract more artists who then successfully lobby for the passage of moral rights legislation. Landes attempts to address the possibility of such a phenomenon by controlling for lagged (1980) values of each outcome variable, ${ }^{6}$ but this solution cannot address those differences between law and non-law states that are not explicitly measured in the data.

We therefore add to the body of empirical evidence in two ways. First, we present a state-level analysis in the same spirit as Landes (2001), but utilizing a difference-indifferences framework to account for unobservable variations in the labor market for artists, between states with moral rights laws and those without. Second, we undertake an analysis with annual, individual-level data. These data provide us with much richer information than the aggregate data used in the state-level analysis, and additionally allow us to estimate the impact of moral rights laws on artists' earnings in a differencein-differences-in-differences framework, thereby adding yet another control group to the study.

\section{State-Level Analysis}

We estimate the impact of moral rights legislation on state-level artists' average income, the number of artists per capita, and state art agency appropriations, using data from the 1980 and 1990 U.S. Census. Summary statistics are reported in Table 1a. As

\footnotetext{
${ }^{6}$ For instance, in the regression with average 1990 artist earnings as an outcome, Landes adds average 1980 artist earnings as a control.
} 
shown in the table, states with moral rights laws are more populous, more urban, and have higher incomes per capita and a higher proportion of residents with bachelor's degrees. In addition, they have a slightly larger number of artists per 1000 population. We estimate the following equation comparing states with moral rights laws to those without moral rights legislation before and after the laws are passed:

$$
y_{s t}=\beta_{0}+\beta_{1} \text { post }_{t}+\beta_{2} \text { law }_{s}+\beta_{3} \text { post }_{t}^{*} \text { law }+\beta_{4} \mathbf{X}_{s t}+\mu_{s t} \text {. }
$$

The variable $y_{s t}$ includes the three outcomes mentioned above, post $_{t}$ is an indicator equal to one in 1990 (the period after all state level-laws have been passed) and 0 in 1980 (the pre-law period), $l a w_{s}$ is an indicator equal to 1 in states with moral rights laws and 0 otherwise. ${ }^{7}$ Finally, $\boldsymbol{X}_{s t}$ is a vector of state characteristics including population, income per capita, percent metropolitan, and percent of adults with a bachelor's degree, and $\mu_{s t}$ is a random error term. The coefficient of interest, $\beta_{3}$, represents the impact of moral rights legislation on the various tested outcome measures, assuming that law and non-law states do not follow different trajectories for the tested outcomes as a result of something other than the moral rights legislation.

Results from estimating equation (1) are reported in Table $2 .{ }^{8}$ In addition to the control variables mentioned above, we include a measure of per capita funding to state arts agencies as a control when the equation is estimated for the average artist earnings outcome (column 1), to proxy for state residents’ attitudes towards the arts. In the

\footnotetext{
${ }^{7}$ As in Landes (2001), California, New York, Massachusetts, Maine, Louisiana, New Jersey, Pennsylvania, Rhode Island and Connecticut are coded as states with moral rights laws. New Mexico, Utah and Montana enacted related legislation during the study period, but as their laws offer only minimal protection we do not include them as moral rights states. Nevada and South Dakota passed moral rights laws in 1989. These are not included as moral rights states in the state-level analysis since income values in the 1990 Census are from the previous year and would not capture the effect of these laws. These two states are included as moral rights states in the individual-level analysis below.

${ }^{8}$ We estimate equation (1) with and without California, since the California law was passed in 1979, and went into effect during the 1980 Census year. Reported results include the California observations, but results are insensitive to the removal of California.
} 
regression with state art agency appropriations on the left-hand side (column 3), we include a control for total state government expenditures per capita, to account for different tastes for public spending that are not captured by the various demographic controls. As shown in the table, the coefficient on post*law is highly statistically insignificant in all cases, a result similar to what Landes (2001) reports for single-year cross-sectional regressions. Thus, in spite of the addition of an extra year of data and a means of controlling for unobservable state-level variation, we are unable to empirically confirm the impact of moral rights legislation using data aggregated to the state level. For this reason, we turn to individual-level annual data, which allows for a richer analysis of two out of the three tested outcomes.

\section{Individual-level Analysis}

To examine the impact of moral rights legislation using individual-level data, we turn to the March Current Population Survey for the years 1977 to 1991 . This dataset is a nationally representative sample containing information on demographic and labor market characteristics of surveyed individuals. The large number of annual cross-sections allows us to exploit the time variation in the passage of the laws (since different states passed laws in different years). With individual- (rather than state-) level data, we are also able to compare outcomes for artists to those for non-artists (whose incomes and locational decisions should be unaffected by moral rights legislation). Using this dataset we are able to examine the impact of moral rights laws on two outcomes - artists’ 
earnings and residence in a moral rights state. We restrict our sample to individuals age 18 to 75 who report being in the labor force. ${ }^{9}$

Summary statistics for this sample are reported in Table 1b. The average ages of artists and non-artists in the sample are similar. Artists are slightly more likely to be male, more likely to be white, and less likely to be married than their non-artist counterparts. In addition, artists are more educated than non-artists but have lower incomes, on average.

To estimate the impact of the laws on artists' earnings, we utilize a difference-indifferences-in-differences (DDD) estimation framework, comparing artists and nonartists in moral rights versus non-moral rights states before and after the passage of the laws. As in the state-level regression, the comparison of individuals in moral rights and non-moral rights states, in the pre- versus post-law periods, controls for underlying differences between states with and those without moral rights laws. The addition of the third difference (artists versus non-artists), allows us to capture changes over time within the labor markets of individual states that happen to coincide with, but are unrelated to, the passage of moral rights legislation.

We estimate the following equation using OLS:

$$
\begin{aligned}
y_{i s t}= & \beta_{0}+\beta_{1} \text { artist }_{\text {ist }} * \text { law }_{s} * \text { post }_{s t}+\beta_{2} \text { artist }_{i s t} * \text { law }_{s}+\beta_{3} \text { artist }_{i s t} * \text { post }_{s t} \\
& +\beta_{4} \text { law }_{s} * \text { post }_{s t}+\beta_{5} \text { artist }_{\text {ist }}+\beta_{6} \text { law }_{s}+\beta_{7} \text { post }_{s t}+\beta_{8} \mathbf{X}_{\text {ist }}+\delta_{t}+\mu_{i s t} .
\end{aligned}
$$

The variable $y_{i s t}$ is the individual's reported income in the previous year, artist $t_{i s t}$ is an indicator equal to 1 if the individual is a painter, sculptor or photographer and 0 otherwise, and $l a w_{s}$ is an indicator equal to 1 in states with moral rights laws, and 0 in states without laws. Post $t_{s t}$ is a dummy equal to 1 in pre-law period and 0 in the post-law

\footnotetext{
${ }^{9}$ This excludes retirees, students, home-makers, and other individuals who are voluntarily not working.
} 
period. In states with laws, this simply amounts to coding the variable equal to 1 in all years following the year in which the law takes effect. ${ }^{10}$ In states without laws, post is coded as equal to 1 in the year after a state in the same Census division enacts a law. If no state in the Census division has moral rights legislation, post is coded as 1 beginning in 1984 (the median year for passage of state moral rights legislation). $\boldsymbol{X}_{i s t}$ is a vector of individual characteristics including gender, race, education, age and marital status dummies, an indicator for location in a metropolitan area, and Census division dummies. Finally, $\delta_{t}$ is a set of year dummies and $\mu_{i s t}$ is a random error term.

The results from estimating equation (2) are reported in the first column of Table 3. The impact of moral rights legislation on artists' earnings is represented by $\beta_{1}$, the coefficient on artist*law*post. As shown in the table, the estimated coefficient is negative and highly statistically significant, supporting the theoretical prediction that moral rights legislation, because of the imposition of contracting costs, leads to a drop in the income of artists. This result indicates that artists living in moral rights states in the post-law period lose $\$ 4250$ per year, on average, as a result of these laws. This is a $22 \%$ decrease relative to the pre-period average artist's income.

In addition to examining the impact of moral rights legislation on artists' income, we investigate whether the laws influence artists’ decisions about where to live. We estimate the following difference-in-differences regression, using a limited probability mode ${ }^{11}$ to compare the likelihood of residence in a moral rights state for artists versus non-artists before and after the passage of moral rights legislation:

\footnotetext{
${ }^{10}$ We do not code $p o s t=1$ in the same year that the law takes effect, because the income variable reports earnings from the previous year.

${ }^{11}$ Since probit estimation produces highly similar results, we report the OLS coefficients for ease of interpretation.
} 


$$
\text { law }_{\text {ist }}=\beta_{0}+\beta_{1} \text { post }_{s t}+\beta_{2} \text { artist }_{\text {ist }}+\beta_{3} \text { artist }_{i s t} * \text { post }_{s t}+\beta_{4} \mathbf{X}_{\text {ist }}+\delta_{t}+\mu_{i s t} .
$$

All variables are defined as in equation (2) above. The coefficient $\beta_{3}$ represents the marginal impact of moral rights laws on the average artist's probability of residing in a moral rights state. If the time and money costs associated with moral rights legislation deter artists from residing in states with laws, then the probability that artists live in moral rights states (i.e the probability that $l a w=1$ for an artist) relative to the probability that non-artists reside in these states should fall in the post-law period (i.e. $\beta_{3}$ should be negative). On the other hand, artists might gain utility from residing in states that demonstrate support for the artistic community through the passage of such laws, and value the protection that these laws provide regardless of the potential contracting costs and lost income that might be associated with such legislation. If so, then artists may seek out residences in moral rights states and the coefficient on $\beta_{3}$ will be positive.

Results from estimating equation (3) are reported in the second column of Table 3. As shown in the table, the coefficient of interest is positive, but extremely small (representing a less than $2 \%$ change relative to the pre-period) and highly statistically insignificant. Thus, it does not appear that artists move, either to or away from states with moral rights legislation as a result of these laws taking effect.

\section{Discussion and Conclusion}

From a theoretical standpoint, it is unclear whether moral rights laws will improve or degrade the economic position of artists. Although Landes (2001) makes a compelling argument for the economic inefficiency of such legislation, that study is unable to establish empirically that the laws are harmful to artists' incomes, or that artists choose 
their locations based on the presence or absence of such legislation. By employing a difference-in-differences (and DDD) framework, we overcome many of the empirical difficulties in Landes' econometric analysis. As such, we are able to confirm his theoretical prediction that the presence of moral rights laws (and the transaction costs associated with waiving these rights) leads to a decrease in artists' incomes. In fact, we find that prior to the passage of VARA, artists in states with moral rights protection lost $\$ 4250$ per year, on average, as a result of these laws.

In spite of this apparent perverse effect of the laws on the population they are intended to help, it remains unclear whether artists will suffer a drop in utility as a result of such protection. It is therefore not obvious, in the years prior to VARA, whether artists should be expected to seek out or avoid states with such protection. On the one hand, the income and time losses associated with contracting may decrease artists' utility enough that they would prefer locations without such legislation. On the other hand, artists may value the protection associated with the laws, and the statement that the laws make (i.e. public support for the artistic community) enough that their net utility rises as a result, in spite of the lost income. In such a case, artists might theoretically seek out residence in states with moral rights protection. Since different artists will likely have different preferences regarding moral rights legislation, it is somewhat unsurprising that our results show no measurable effect of state-level moral rights laws on artists' choices of location.

While this study empirically estimates the impact of moral rights laws on artists, we are not able to statistically capture the non-monetary impact of these laws on artists or the public. In addition, as discussed by Towse (2006), artists' earnings do not necessarily correlate with creativity, and thus we are unable to discern the impact of these laws on 
the level of artistic innovation. In spite of our inability to undertake a complete welfare analysis, however, we do establish that moral rights laws have a negative consequence for the population they are primarily intended to protect. As such, future reconsideration of VARA by policymakers may be warranted as the application of the law does not appear to correspond to its original objective. 
Table 1a. Summary Statistics - State-Level Analysis

\begin{tabular}{|l|c|c|c|c|}
\hline & \multicolumn{2}{|c|}{1980} & \multicolumn{2}{c|}{1990} \\
& Law & Non-Law & Law & Non-Law \\
\hline population (millions) & 8.407 & 3.600 & 9.211 & 3.933 \\
& $(7.850)$ & $(3.289)$ & $(9.403)$ & $(3.695)$ \\
\hline income per capita & 14554.05 & 14353.79 & 19146.17 & 16780.68 \\
& $(1574.557)$ & $(.271)$ & $(3196.141)$ & $(2441.904)$ \\
\hline proportion metropolitan & .653 & .513 & .633 & .504 \\
& $(.244)$ & $(.271)$ & $(.314)$ & $(.275)$ \\
\hline proportion w/4-year degree & .102 & .092 & .145 & .123 \\
& $(.019)$ & $(.021)$ & $(.029)$ & $(.027)$ \\
\hline gov't expenditures per capita & 1721.518 & 1775.46 & 2419.111 & 2158.439 \\
& $(220.951)$ & $(996.844)$ & $(366.803)$ & $(995.889)$ \\
\hline art agency appropriations per capita & .786 & .607 & 1.477 & 1.045 \\
& $(.849)$ & $(1.037)$ & $(1.161)$ & $(1.291)$ \\
\hline artists per 1000 population & 1.429 & 1.168 & 1.915 & 1.575 \\
& $(.478)$ & $(.438)$ & $(.446)$ & $(.514)$ \\
\hline average artist earnings & 16775.45 & 16025.94 & 21072.61 & 17270.32 \\
& $(2710.367)$ & $(2361.804)$ & $(4810.942)$ & $(3141.552)$ \\
\hline Observations & 9 & 42 & 9 & 42 \\
\hline
\end{tabular}

Statistics are means (standard deviation in parentheses). All dollar values are in 1990 dollars. Art agency appropriations from National Assembly of State Arts Agencies Public Funding Sourcebook, gov't expenditures per capita from Statistical Abstract of the United States (1981 and 1992 editions). All other variables from U.S. Census.

Table 1b. Summary Statistics - Current Population Survey

\begin{tabular}{|l|c|c|c|c|}
\hline & \multicolumn{2}{|c|}{ Artist } & \multicolumn{2}{c|}{ Non-artist } \\
\hline & Pre & Post & Pre & .294 \\
\hline residence in law state & .422 & .359 & .359 & 37.733 \\
& & & & $(12.715)$ \\
\hline age & 37.241 & 37.688 & 37.715 & .550 \\
& $(13.074)$ & $(12.218)$ & $.13 .519)$ & .494 \\
\hline male & .597 & .566 & .894 & .672 \\
\hline white & .945 & .929 & .661 & .223 \\
\hline married & .596 & .540 & .187 & 21208.69 \\
\hline 4-year degree & .379 & .430 & & $(18566.54)$ \\
\hline
\end{tabular}

Data from 1977-1991 March CPS. Statistics are means (standard deviation in parentheses). Income is measured in 1989 dollars. Sample includes individuals 18-75 years old and in the labor force. Artists include painters, sculptors and photographers. "Pre" $=1$ in the pre-law period, "post" $=1$ in the post-law period. 
Table 2. State-Level Analysis

\begin{tabular}{lccc}
\hline & $(1)$ & $(2)$ & $(3)$ \\
\hline \multirow{2}{*}{ post*law } & Avg Artist Earnings & Artists per 1000 Population & Art Agency Appropriations \\
post & $\mathbf{8 2 0 . 3 0 3}$ & $\mathbf{- 0 . 0 0 5}$ & $\mathbf{0 . 2 1 5}$ \\
& $\mathbf{( 9 5 3 . 0 8 1 )}$ & $\mathbf{( 0 . 1 3 0 )}$ & $\mathbf{( 0 . 4 0 1 )}$ \\
law & $-1,252.079^{*}$ & 0.055 & 0.143 \\
& $(489.823)$ & $(0.065)$ & $(0.247)$ \\
population & 881.378 & -0.088 & $-0.517^{*}$ \\
& $(856.167)$ & $(0.077)$ & $(0.251)$ \\
income per capita & $98.146^{*}$ & 0.004 & -0.020 \\
& $(40.177)$ & $(0.005)$ & $(0.037)$ \\
metro & $0.998^{* *}$ & $-0.00004+$ & -0.00007 \\
& $(0.144)$ & $(0.00002)$ & $(0.00006)$ \\
college & 898.700 & $0.465^{* *}$ & $1.227^{* *}$ \\
& $(1,786.689)$ & $(0.149)$ & $(0.395)$ \\
art agency appropriations & -940.187 & $14.489 * *$ & 4.210 \\
gov't expend. per capita & $(11,063.548)$ & $(2.484)$ & $(5.942)$ \\
observations & 182.202 & & \\
R-squared & $(260.830)$ & & $0.001^{*}$ \\
\hline Resits & & & $(0.000)$ \\
\end{tabular}

Results from estimating equation (1) by OLS. Robust standard errors in parentheses. Law is equal to 1 if the state passed moral rights legislation and 0 otherwise. Post is equal to 1 in 1990 and 0 in 1980. Art agency appropriations is a measure of per capita state government funding for state arts agencies. Gov't expend. per capita is total state government expenditures per capita. All dollar values are adjusted to 1990 dollars. Column (3) does not include data for Washington, DC. + significant at 10\%; * significant at 5\%; ** significant at $1 \%$ 
Table 3. Individual-Level Analysis

\begin{tabular}{|c|c|c|}
\hline & (1) & (2) \\
\hline & Income & Moral Rights State \\
\hline artist*law*post & $\begin{array}{l}-4,250.090^{* *} \\
(1,191.086)\end{array}$ & \\
\hline artist $^{*}$ post & $\begin{array}{c}-19.420 \\
(730.452)\end{array}$ & $\begin{array}{c}0.008 \\
(0.010)\end{array}$ \\
\hline post & $\begin{array}{c}-782.803 * * \\
(69.195)\end{array}$ & $\begin{array}{l}-0.197 * * \\
(0.002)\end{array}$ \\
\hline artist & $\begin{array}{l}-5,703.832 * * \\
(524.502)\end{array}$ & $\begin{array}{l}-0.004 \\
(0.008)\end{array}$ \\
\hline law & $\begin{array}{c}-571.641 * * \\
(58.518)\end{array}$ & \\
\hline post*law & $\begin{array}{c}1,658.493^{* *} \\
(64.035)\end{array}$ & \\
\hline artist*law & $\begin{array}{l}2,862.112^{* *} \\
(822.302)\end{array}$ & \\
\hline male & $\begin{array}{l}11,184.081^{* *} \\
(26.244)\end{array}$ & $\begin{array}{l}-0.000 \\
(0.001)\end{array}$ \\
\hline white & $\begin{array}{c}2,819.872^{* *} \\
(37.086)\end{array}$ & $\begin{array}{l}0.006 * * \\
(0.001)\end{array}$ \\
\hline married & $\begin{array}{c}1,698.415^{* *} \\
(30.441)\end{array}$ & $\begin{array}{l}-0.016 * * \\
(0.001)\end{array}$ \\
\hline Observations & 1114837 & 1114837 \\
\hline R-squared & 0.33 & 0.64 \\
\hline
\end{tabular}

Column (1) reports results from estimating equation (2) by OLS. Column (2) reports results from estimating equation (3) by OLS. Robust standard errors in parentheses. Regression universe is individuals ages 18 to 75 and in the labor force. Regressions also include year, Census division, education and age dummies. Artist is equal to 1 if the individual is a painter, sculptor or photographer and 0 otherwise. Post is equal to 1 in post-law years. Law is equal to 1 for states with moral rights legislation.

+ significant at 10\%; * significant at 5\%; ** significant at $1 \%$ 


\section{References}

Chang, RayMing (2004). "Revisiting the Visual Artists Rights Act of 1990: A Follow-up Survey About Awareness and Waiver,” Texas Intellectual Property Law Journal. Vol. 13(129), 129-170.

Failing, Patricia (2002). "Artists Moral Rights in the United States before VARA/1990: An Introduction,” Panel Discussion: The Committee on Intellectual Property of the College Art Association. Retrieved June 24, 2008 from http://www.studiolo.org/CIP/VARA/Failing/Failing.htm

Hansmann, Henry and Marina Santilli (1997). “Authors’ and Artists’ Moral Rights: A Comparative Legal and Economic Analysis,” Journal of Legal Studies. Vol. 26, 95-143.

King, Miriam et al. Integrated Public Use Microdata Series, Current Population Survey:Version 2.0. [Machine-readable database]. Minneapolis, MN: Minnesota Population Center [producer and distributor], 2004. cps.ipums.org/cps

Landes, William M. (2001). "What Has the Visual Artist’s Rights Act of 1990 Accomplished?,” Journal of Cultural Economics. Vol. 25, 283-306.

Landes, William M. and Daniel B. Levine (2006). "The Economic Analysis of Art Law,” Handbook of the Economics of Art and Culture. Vol. 1, 211-251.

National Assembly of State Arts Agencies. Annual Appropriations and Revenue Survey Data.

Ruggles, Steven et al. Integrated Public Use Microdata Series: Version 4.0 [Machinereadable database]. Minneapolis, MN: Minnesota Population Center [producer and distributor], 2008. http://usa.ipums.org/usa/

Rushton, Michael (1998). “The Moral Rights of Artists: Droit Moral ou Droit Pécuniaire?,” Journal of Cultural Economics. Vol. 22, 15-32.

Rushton, Michael (2001). “The Law and Economics of Artists’ Inalienable Rights,” Journal of Cultural Economics. Vol. 25, 243-257.

St. Louis Volunteer Lawyers and Accountants for the Arts (2005). “Artist's Guide to the Visual Artists Rights Act: Your (Limited) Moral Rights.”

Towse, Ruth (2006). “Copyright and Creativity: An Application of Cultural Economics,” Review of Economic Research on Copyright Issues. Vol. 3(2), 83-91.

U.S. Bureau of the Census. Statistical Abstract of the United States: 1981 (102 ${ }^{\text {nd }}$ edition). Washington, DC 1981 
U.S. Bureau of the Census. Statistical Abstract of the United States: 1992 (112 ${ }^{\text {th }}$ edition). Washington, DC 1992

U.S. Copyright Office. Waiver of Moral Rights in Visual Artworks: Executive Summary 10/24/96. Retrieved June 27, 2008 from http://www.copyright.gov/reports/exsum.html

Visual Artist's Rights Act of 1990, Pub. L. No. 101-650, Title VI, 104 Stat. 5128 (1990) (codified at 17 U.S.C. $\S \S 101,106$ A, 107, 113, 301, 411, 412, 501, 506). 